\title{
Study on Ultrasonic Response to Mechanical Structure of Coal under Loading and Unloading Condition
}

\author{
Xiaofei Liu, ${ }^{1,2}$ Xiaoran Wang, ${ }^{1,2}$ Enyuan Wang, ${ }^{1,2}$ Zhentang Liu, $^{2}$ and Xiaoyang Xu ${ }^{2}$ \\ ${ }^{1}$ Key Laboratory of Coal Mine Gas and Fire Prevention and Control of the Ministry of Education, China University of Mining and \\ Technology, Xuzhou, Jiangsu 221116, China \\ ${ }^{2}$ School of Safety Engineering, China University of Mining and Technology, Xuzhou, Jiangsu 221116, China
}

Correspondence should be addressed to Enyuan Wang; weytop@cumt.edu.cn

Received 25 June 2016; Revised 14 October 2016; Accepted 31 October 2016; Published 9 January 2017

Academic Editor: Vadim V. Silberschmidt

Copyright (C) 2017 Xiaofei Liu et al. This is an open access article distributed under the Creative Commons Attribution License, which permits unrestricted use, distribution, and reproduction in any medium, provided the original work is properly cited.

\begin{abstract}
Ultrasonic technology can be applied to study the changes in the internal defects of coal under quantitative loading, which can provide the theoretical basis for applying the technology to determine the structural stability of coal and predict disasters related to the dynamics of coal or rock. In this paper, to investigate the propagation laws of ultrasonic signals through a coal material under various loading conditions, an ultrasonic test system for the deformation and fracture of coal rock was used and a cyclic loading and unloading pattern is adopted. In addition, changes in ultrasonic parameters such as amplitude, dominant frequency, and velocity were analyzed. At the initial loading stage, the ultrasonic amplitude, amplitude of the dominant frequency, and wave velocity slightly decrease as the loading process progresses, and these three ultrasonic parameters gradually increase to their maxima when the stress level reaches approximately $46 \%$. When it progresses from the linear elastic stage to the elastic plastic stage, the material inside the coal distorts and fractures more drastically, the inner defects are fully developed, and the acoustic parameters decrease significantly. Therefore, the corresponding measures should be adapted to reduce the loading stress before the coal is loaded to its critical stress level.
\end{abstract}

\section{Introduction}

Coal, an anisotropic compound consisting of various natural minerals, is formed naturally in geologic conditions. The inner structure of coal is damaged to various extents and has different forms. When load pressure is applied, different defects arise, causing changes in the structural pattern of coal $[1,2]$. Thus, it is necessary to analyze the changes in the internal structure of coal under load pressure using a specific technical measure [3-6].

In the past few years, various laboratory techniques [712] such as scanning electron microscopy (SEM) [7], infrared thermal imaging [8], computerized tomography (CT) [9, $10]$, and acoustic emission (AE) [11, 12] have been used to observe the damage process of coal or rock materials under load pressure. However, the application of these techniques to practical situations is difficult owing to rigorous test conditions, expensive infrastructure, and facilities. Besides, the location accuracy of the AE source was not high because of the effect of AE sensor array [13], P-wave velocity [14], and other factors. As a nondestructive, rapid, and simple detection method, ultrasonic testing is increasingly used in laboratory and field tests $[15,16]$. Lokajíček and Svitek designed and constructed a new high-pressure measuring head to test longitudinal and transversal ultrasonic sounding of spherical rock samples in 132 independent directions under confining pressure between $0.1 \mathrm{MPa}$ and $60 \mathrm{MPa}$ and studied the elastic anisotropy of loaded rocks [17]. Using ultrasonic P-wave reflection imaging technology, Coe and Brandenberg clearly observed the geometric features of the internal structure of rock-soil samples. They determined that the higher the frequency of the transducer, the clearer the observed result of the internal structure [18]. Peyras et al. used the amplitude of acoustic waves to determine and characterize the discontinuity openings of metamorphic rock mass [19]. In the process of loading, the internal strain of rock or coal samples will exhibit relaxation properties, and the ultrasonic velocity variation can be seen as an 


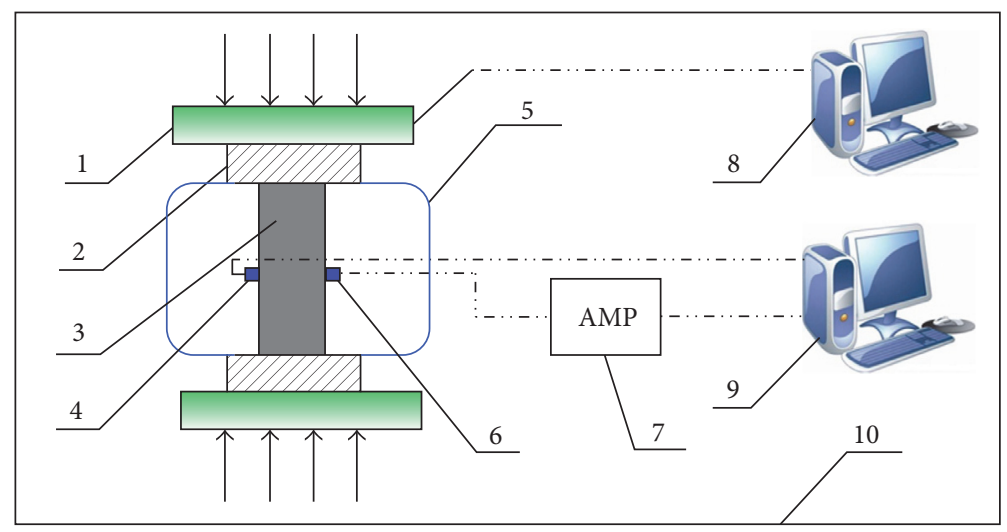

FIGURE 1: Schematic diagram for ultrasonic testing of coal samples. 1: compression testing machine, 2: support block, 3: sample, 4: ultrasonic transducer, 5: shielding system, 6: AE receiving probe, 7: preamplifiers, 8: loading control system, 9: ultrasonic signals emission and acquisition system, and 10: electromagnetic shielding room.

TABLE 1: The coal type and composition.

\begin{tabular}{lccccrr}
\hline Coal sample & $\mathrm{Ad} / \%$ & Vadf/\% & $\mathrm{Mad} / \%$ & $\mathrm{St} . \mathrm{d} / \%$ & Hardness & Type \\
\hline Sanhejian & $8.78-32.41$ & $36.43-42.69$ & $0.60-3.89$ & $0.39-1.02$ & $2-3$ & Gas coal \\
\hline
\end{tabular}

indicator of rock stress relaxation [20]. Engelder and Plumb [21] studied the changing pattern of ultrasonic wave velocity under the condition of uniaxial loading, using wave tests to describe the relation between wave velocity and stress. Nur [22] studied and discussed the response characteristics of ultrasonic wave velocity to the loading stress level. Zheng et al. [23] established a correspondence between wave velocity and rock damage variable during uniaxial compression.

Ultrasonic wave attenuation occurs during the process of ultrasonic wave transmission in media; the attenuation is the loss of ultrasonic vibrational energy [24]. Xi et al. [25] determined the relations between the attenuation of the phase velocity of elastic waves and many parameters such as elastic constant of the solid phase, porosity, permeability, saturation, flow viscosity, compressibility, and frequency. Dvorkin and Nur [26] derived the theoretical formulas for P-wave velocity and attenuation of sandstone samples under different pressure, and he carried out experiments to verify theoretical formulas. Diallo et al. [27] used the ultrasonic of a certain frequency to study the $\mathrm{P}$-wave, $\mathrm{S}$-wave, and the attenuation characteristics of sandstone and limestone samples, and he obtained the ultrasonic attenuation absorption mechanism of rock.

Research in this filed has included theoretical analyses, experimental studies, numerical simulations, and so forth, on the propagation/attenuation of elastic waves in different media. However, overall, they have the following shortcomings: (1) the attenuation of an elastic wave is closely correlated with the propagation media. Whereas studies on the ultrasonic wave propagation patterns and characteristics in anisotropic media such as coal are relatively rare, there is a need to carry out more studies in this regard. (2) At present, studies tend to analyze only the velocity of ultrasonic waves to evaluate material defects. However, there is a lack of studies on sound parameters (e.g., amplitude and dominant frequency), which are very sensitive to the level of defect. So, in the paper, we evaluated the propagation of ultrasonic waves in coal under load pressure and collected various sound parameters of ultrasonic waves and analyzed the association between ultrasonic wave propagation and stress strain of coal; in addition, the relation between the mechanical properties of coal or rocks and their inner cracks was analyzed. Ultrasonic parameters can precisely reflect the inner changes in coal structure, which can serve as a theoretical basis for using ultrasonic waves to predict the dynamic hazards of coal or rocks.

\section{Experimental System of Ultrasonic Testing}

2.1. Experimental System and Samples. The experimental system consists of the loading system (servocontrolled mechanical test equipment YAW4306), ultrasonic wave signals emission (ARB-1410 cards), and acquisition system (the PCI-2 AE and ultrasonic data-acquisition systems). A schematic of the experimental system is shown in Figure 1.

The experiment samples are the original coal masses. We collect the lump original coal masses from Sanhejian coal mine site and use the drilling machine to get cylindrical specimens and then use the cutting machine to process into standard cylinder samples $(\phi 50 \mathrm{~mm} \times 100 \mathrm{~mm})$. To ensure that the surface flatness error on both ends is less than $0.02 \mathrm{~mm}$, the ends are grinded using a surface grinding machine. The coal types in our experiment are hard gas coal which have a bursting liability. And the coal composition is shown in Table 1 . We prepared for 15 coal samples (Figure 2(a)) and picked out over 5 intact coal samples (Figures 2(b) and 2(c)) to test ultrasonic response characteristics under cyclic loading and unloading process. 


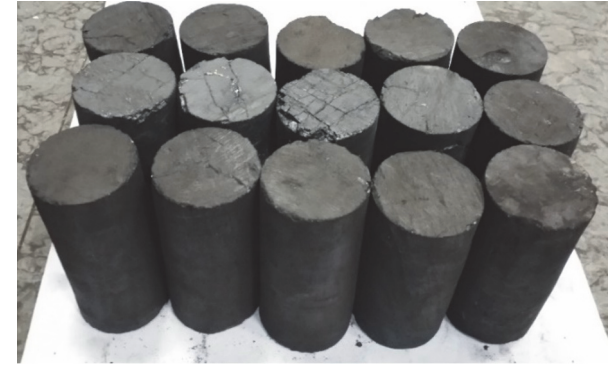

(a)

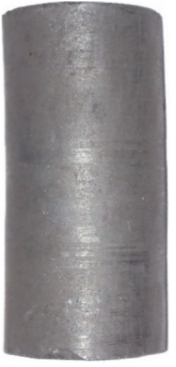

(b)

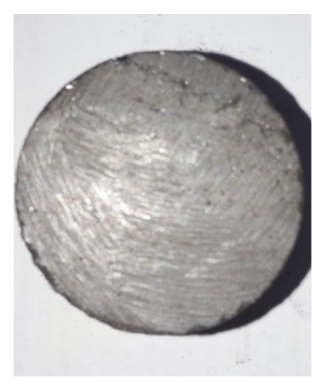

(c)

FIGURE 2: The physical figures of coal samples.
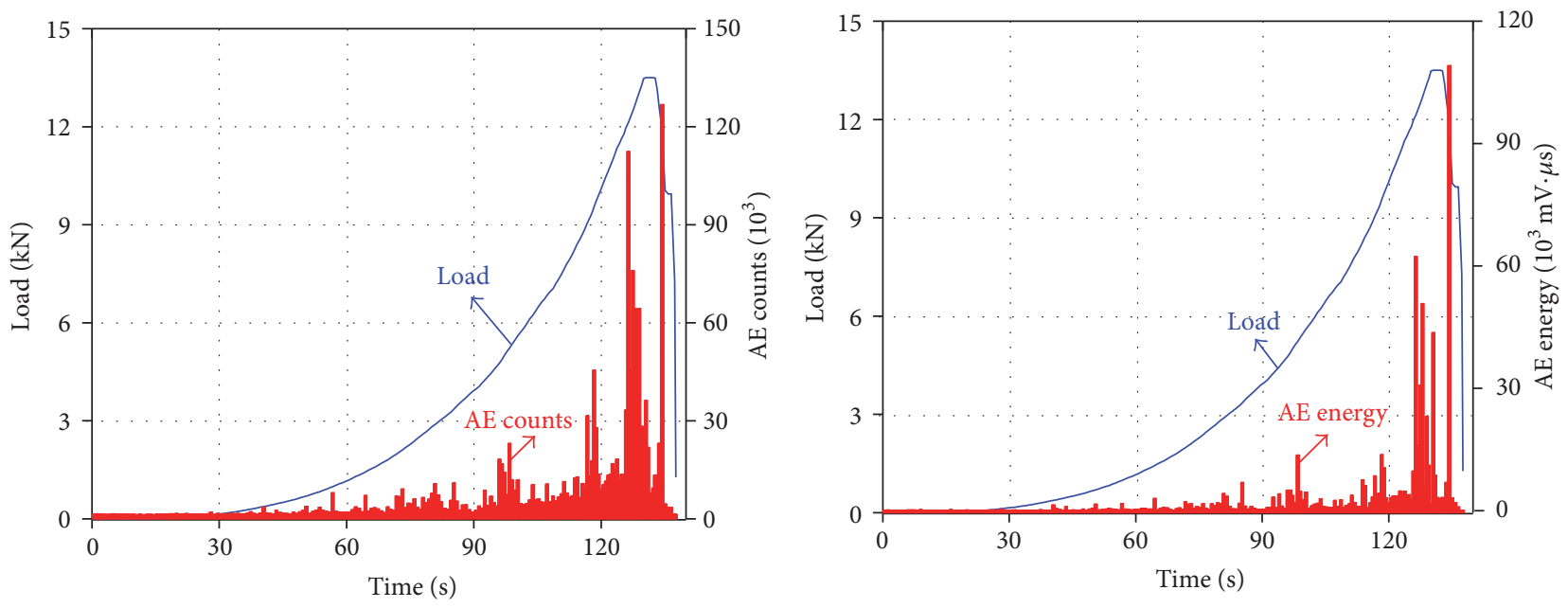

FigURE 3: AE characteristics of coal samples under uniaxial compression.

2.2. Test Program. In the experiments, we mainly studied the relationship between the mechanical structures of the coal samples and the ultrasonic wave parameters. When the force acts on the coal samples during the loading process, the internal structure of coal will generate acoustic emission (AE) signals, which can seriously affect the reception of ultrasonic signals. To solve this problem, the cyclic loading and unloading process was carried out in the experiments in order to reduce the impact of the acoustic emission signals in the loading process.

2.2.1. AE Filtering Principles and Results. In the process of rupture of coal under loading, it will generate acoustic emission (AE) signals inside the coal inevitably. The $\mathrm{AE}$ characteristics of coal samples under uniaxial compression are shown in Figure 3. From Figure 3 we can know that, as the loading pressure increases, $\mathrm{AE}$ signals again begin to increase and reach their maximum when the cracks break.

However, in the process of cyclic loading and unloading, the AE signal of coal samples shows an obvious Kaiser Effect [28]. The cause of the AE Kaiser Effect can be explained as follows. At the deformation and failure process of the coal or rock materials, AE signals generate mainly by the formation and expansion of cracks. When a load is applied to coal or rock samples that have been exposed to certain stress, some microunit has been broken, and this breakdown is irreversible; thus, below this stress level microfracturing will not occur again and there will be no AE signals. Only when the load applied to samples is larger than the historical maximum stress, will AE signals appear again $[29,30]$. Based on the principles of the Kaiser Effect, a cyclic loading and unloading pattern is adopted to reduce the effect of $\mathrm{AE}$ signals on the ultrasonic test.

The results of the AE filtering experiment on coal samples under loading and unloading conditions are shown in Figure 4. From the experiment, it can be seen that, under constant loading, the coal samples will produce much significantly fewer AE signals which, at some loading levels, can even reach the same degree of initial environmental noise. We partially enlarge the AE signals in the period of time within $380-810 \mathrm{~s}$ and compare them with the initial environmental signals, as shown in Figure 4(b). It can be seen from the figure that, in the loading time 380-810 s, because the applied load is not greater than the historical maximum load, the $\mathrm{AE}$ pulse counts are between 0 and 7 , and the $\mathrm{AE}$ energy is 0 $1.3 \mathrm{mV} \cdot \mu \mathrm{s}$, and their values are commensurate with the level of environmental noise. Thus, this result confirms that using the cyclic loading and unloading test can reduce the effect of $\mathrm{AE}$ signals on the ultrasonic test under loading conditions. 

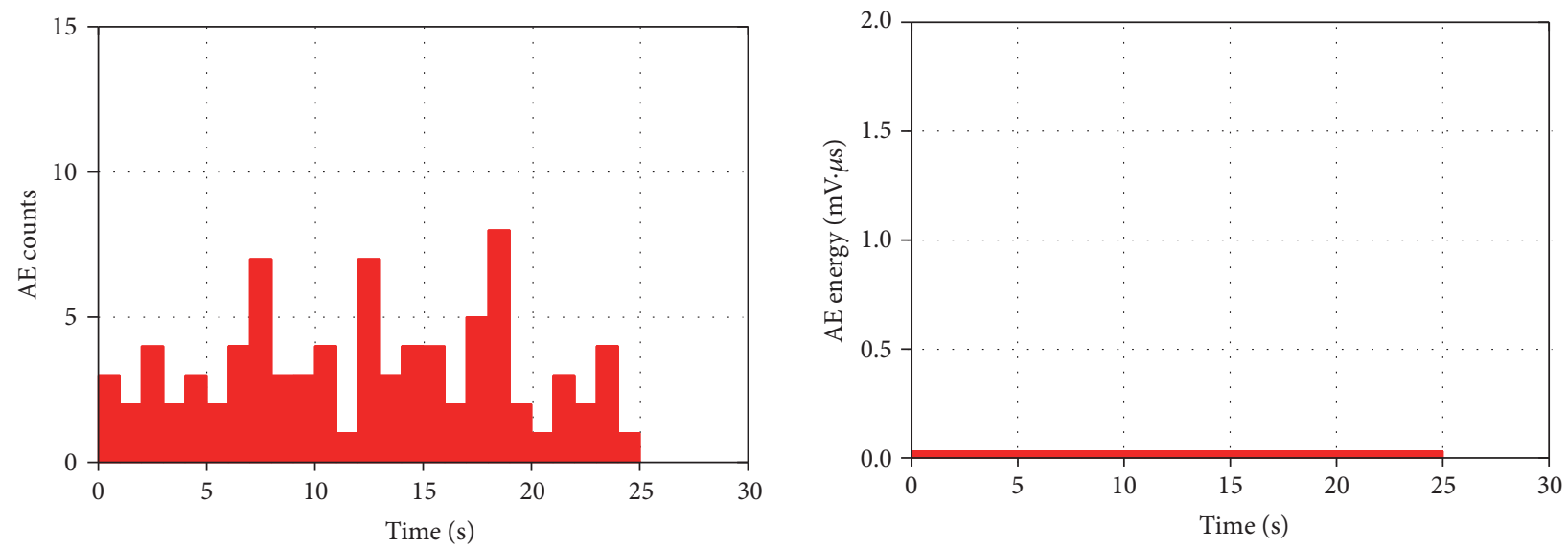

(a) Environmental noise signals
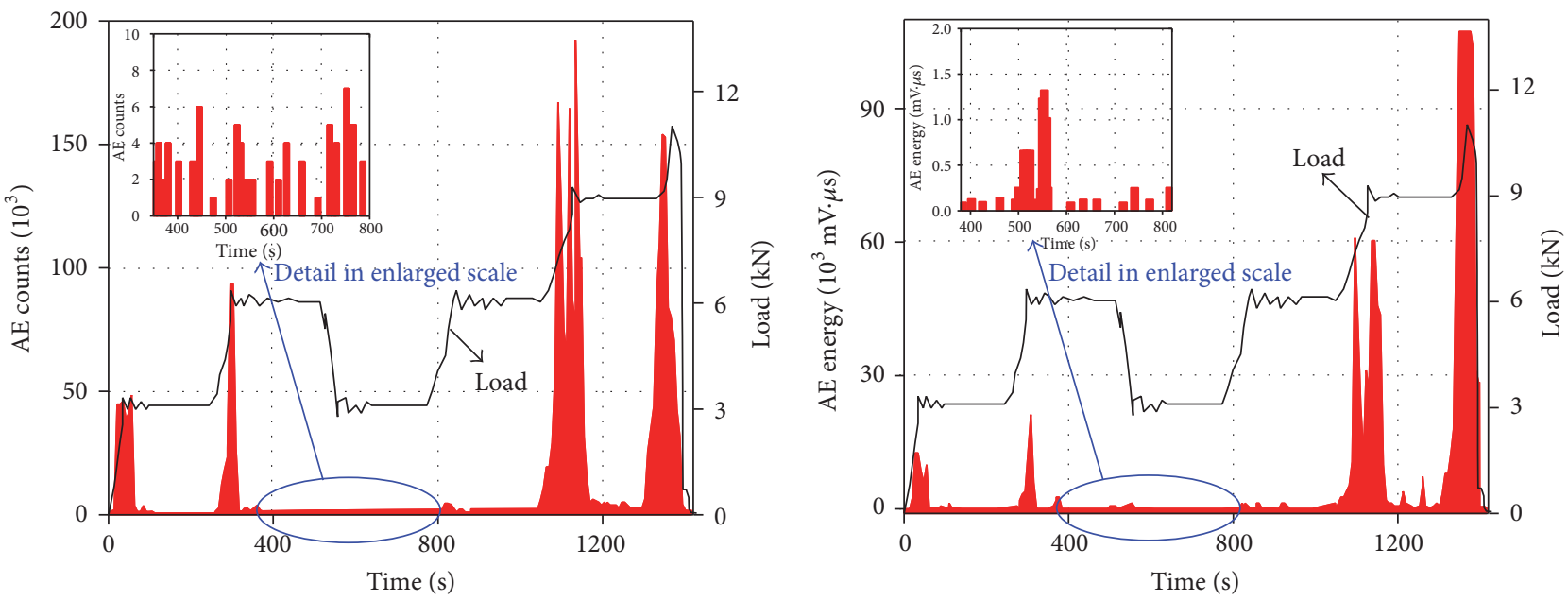

(b) Experimental results of cyclic loading and unloading

FIGURE 4: The AE filtering experiment results of coal under loading and unloading.

2.2.2. Cyclic Loading and Unloading Process. Based on the results of $\mathrm{AE}$ filtering experimental results, the loading process for the ultrasonic test experiments carried out in this study is as follows: (1) measure the ultrasonic wave parameters before the process of loading, (2) load up to $1.5 \mathrm{kN}$ and maintain the force for 3-4 minutes; (3) load up to $4.5 \mathrm{kN}$ and maintain the force for 3-4 minutes; (4) unload up to $1.5 \mathrm{kN}$ and maintain the force for 3-4 minutes; (5) load up to $7.5 \mathrm{kN}$ and maintain the force for 3-4 minutes; (6) unload up to $4.5 \mathrm{kN}$ and maintain the force for 3-4 minutes; (7) load up to $9 \mathrm{kN}$ and maintain the force for 3-4 minutes; (8) load up to the maximum stress (i.e., up to the point the coal samples produce damage) and unload completely.

\section{Response of Ultrasonic Signals to Mechanical Structure of Coal Samples}

3.1. The Generated Ultrasonic Signals and Processing of Experimental Data. The figures of waveform and its spectrum for the emission ultrasonic signals generated by the waveform generation system (ARB-1410 cards) are as shown in Figure 5.
The generated ultrasonic signals is sine wave and the dominant frequency of the emission ultrasonic signals is $30 \mathrm{kHz}$. The detailed information of signals to be generated for testing is shown in Table 2.

The ultrasonic signals are analyzed based on their frequency spectra, which is obtained via Fast Fourier Transform (FFT). This reveals the relation between the frequency spectrum characteristic of the ultrasonic signals, the physical and mechanical properties of coal samples, and the stress strain and intrinsic defects within the coal material.

During the sampling process, the signals are in a discrete sequence, which necessitates application of a discrete Fourier Transform. The discrete Fourier Transform of discrete time series $f_{0}, f_{1}, \ldots, f_{N-1}$ is as follows:

$$
X(k)=F\left(f_{n}\right)=\sum_{n=0}^{N-1} f_{n} e^{-i(2 \pi k / N) n},
$$

$$
k=0,1, \ldots, N-1,
$$

where $X(k)$ and $F\left(f_{n}\right)$ are the $N$-point discrete Fourier Transform of finite series $f_{n} ; k$ is the sampling point moment 


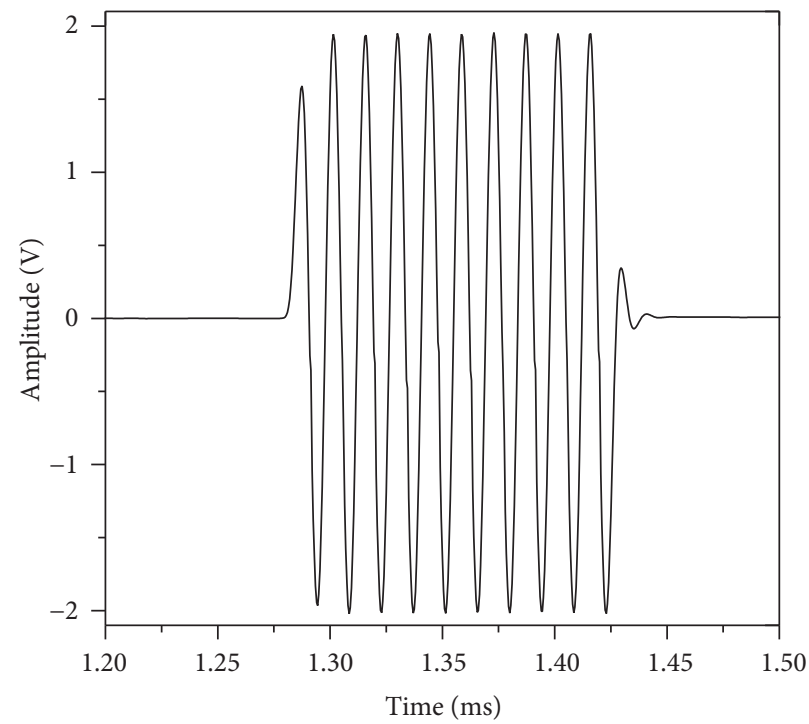

(a) Waveform

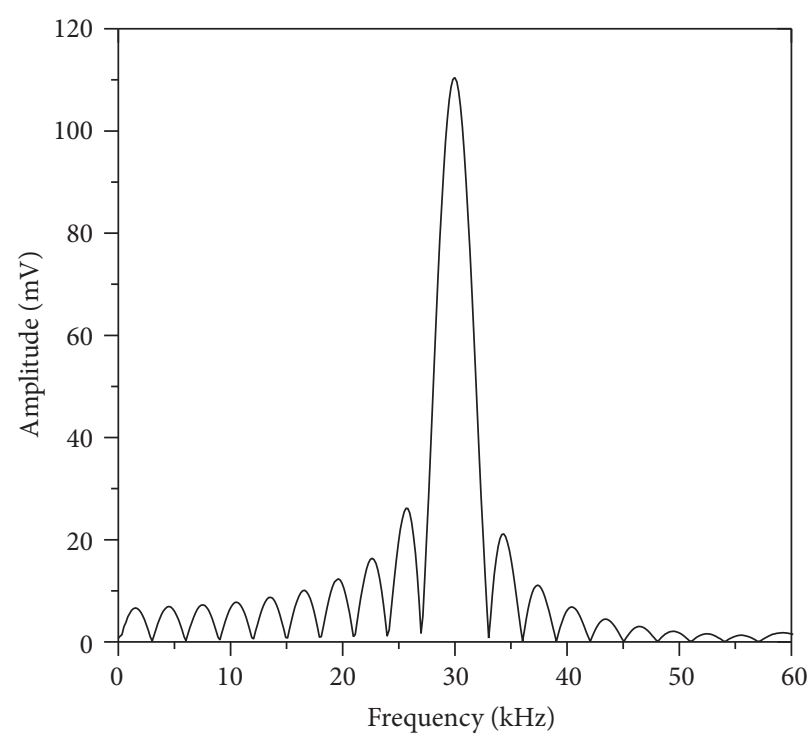

(b) Spectrum

FIGURE 5: The waveform and spectrum for the generated ultrasonic.

TABLE 2: The detailed information of the generated ultrasonic signals.

\begin{tabular}{lcccccc}
\hline Waveform & Dominant frequency & Firing interval & Threshold & Sampling frequency & Fluctuation amplitude & Waveform length \\
\hline Sine wave & $300 \mathrm{kHz}$ & $2 \mathrm{~s}$ & $40 \mathrm{~dB}$ & $500 \mathrm{ksps}$ & $2 \mathrm{~V}$ & $1 \mathrm{k}$ \\
\hline
\end{tabular}

in the frequency domain, where the sampling moments are $0,1, \ldots, N-1$, respectively.

\subsection{Ultrasonic Test of Coal during the Process of Cyclic Loading} and Unloading. Under the condition of cyclic loading and unloading for the study of the relation between ultrasonic parameters and fracture structures inside coal samples, three sets of tests were conducted and the typical experimental results are shown in Figure 6.

Figure 6(c) shows the ultrasonic testing results of coal before loading. When ultrasonic signals propagate in coal, their energy is largely weakened, with only $10-20 \%$ successfully reaching the receiver. The inner structure of coal loosens, showing microcracks and microfractures. When the ultrasonic wave propagates in this region, it generates diffraction upon encountering relatively small cracks, which would significantly reduce the received sound energy.

During the initial loading process, the microcracks and holes inside the samples undergo loading pressure, and they begin to transform and close. From the macroscopic angle, cracks inside the coal tend to decrease, and the coal structure tends to be stable. When the ultrasonic wave propagates in the coal sample, sound energy is largely absorbed. Compared with the unloading state, the sound parameters of the wave improve. In addition, the sound fluctuation amplitude and dominant frequency amplitude are slightly reduced (Figure 6(d)).

When subjected to further loading pressure, coal samples enter a temporary linear elastic stage in which all microcracks are completely closed. At this stage, the deformation increases with increasing loading pressure. When an ultrasonic wave propagates in this sample, only a few defects are encountered. In addition, the least amount of scattering sound energy is absorbed, and more ultrasonic energy can thus propagate through the testing samples to eventually reach the receiver. In the spectrogram shown in Figures 6(e) and 6(f) it can be seen that, at this stage, the waveforms are stable and continuous and that the amplitude reaches its peak. The speed of sound is relatively the highest; the dominant frequency remains constant and the amplitude also has a high value.

As the loading pressure increases, displacement and dislocation are generated among mineral particles, microcracks, and mineral impurities, generating new damage and destruction inside the coal. The number and extent of cracks generated inside the coal increases drastically and the cracks continue to develop and these cracks then begin to connect with each other. In Figure 6(g), as the ultrasonic signals propagates inside the coal, the ultrasonic energy is largely weakened; ultrasonic signals first begin to disappear randomly, followed by the appearance of scrambled waveforms containing spinulose fluctuations and their amplitude and dominant amplitude both drastically decrease.

When the loading pressure of coal reaches its peak intensity, microcracks are connected to form macrocracks. As pressure increases, macrocracks quickly start to increase and then they join together and finally form fractures. At this stage, the ultrasonic signals are completely reflected and scattered and only a few reach the receiver (Figure 6(g)). So, the ultrasonic waves disappear at random, and massive malformation waveforms are formed; the dominant 


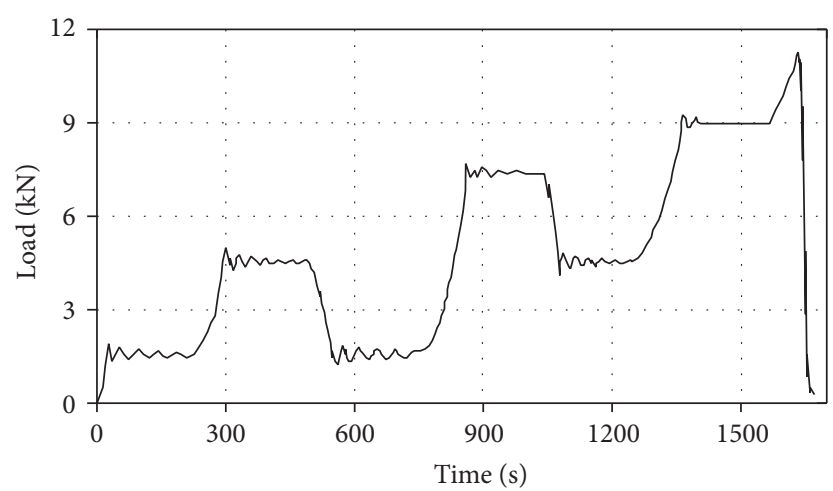

(a) Cyclic loading and unloading pattern

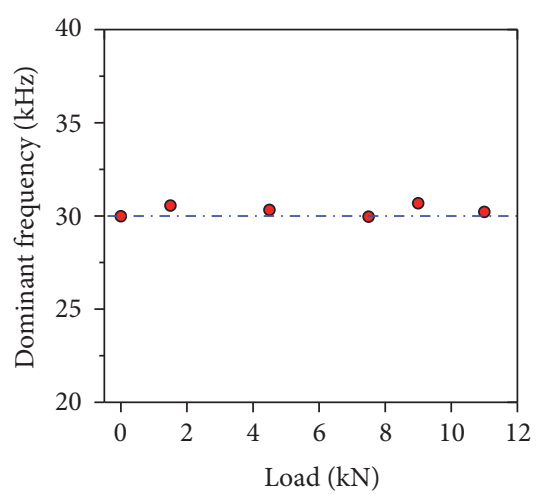

(b) Dominant frequency response
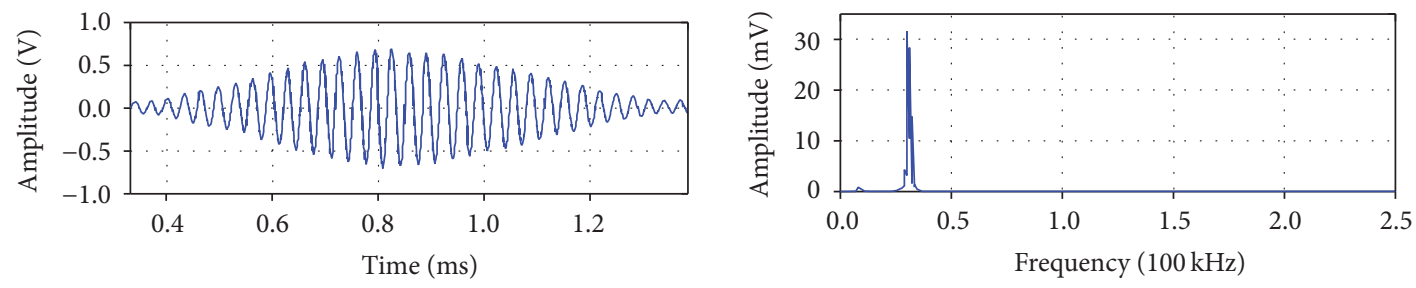

(c) Ultrasonic testing results of coal before loading
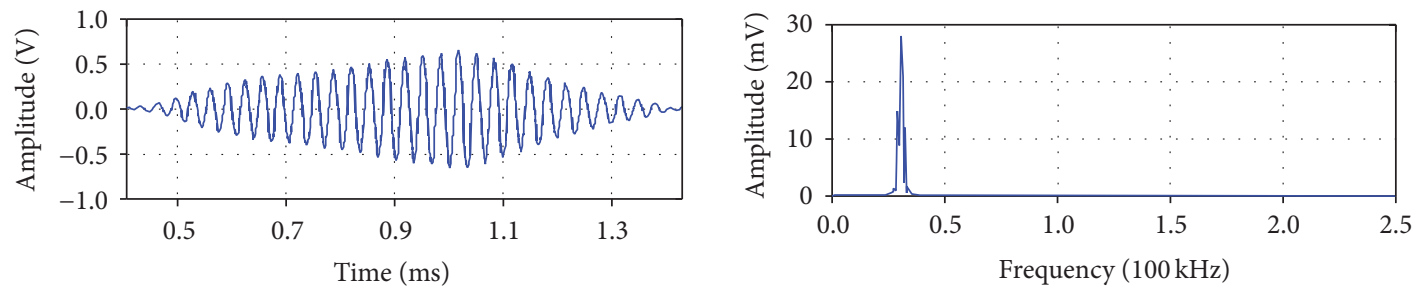

(d) Ultrasonic testing results under the force of $1.5 \mathrm{kN}$
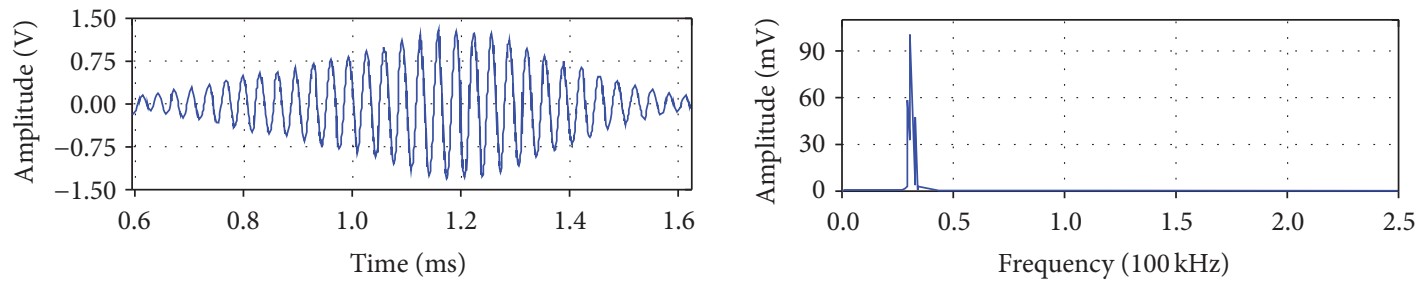

(e) Ultrasonic testing results under the force of $4.5 \mathrm{kN}$
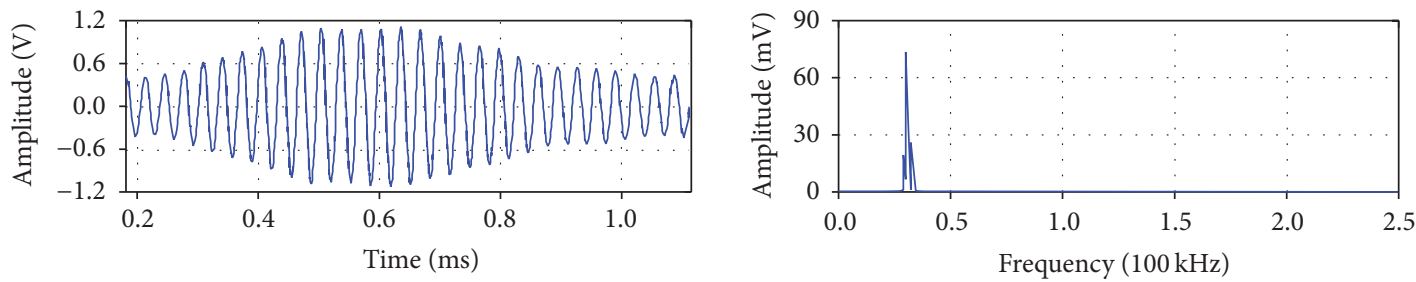

(f) Ultrasonic testing results under the force of $7.5 \mathrm{kN}$
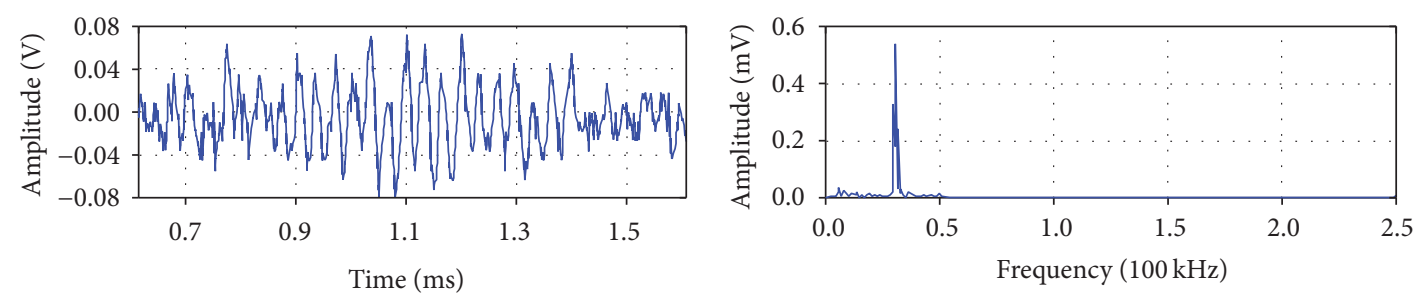

(g) Ultrasonic testing results under the force of $9 \mathrm{kN}$

FIgURE 6: Continued. 

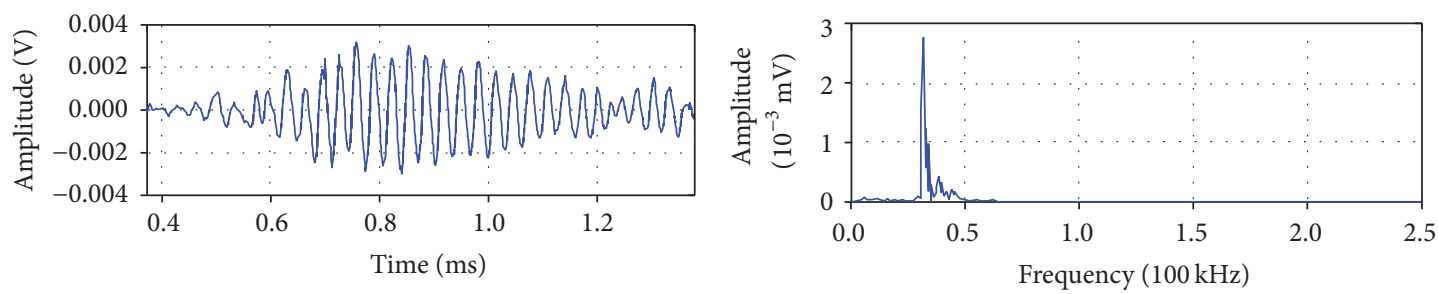

(h) Ultrasonic testing results under the force of $11 \mathrm{kN}$

FIGURE 6: Experimental results for coal samples under cyclic loading.

frequency and wave period basically remain constant, and the ultrasonic waves' amplitude and dominant frequency amplitude decrease drastically, reaching their lowest values before fracturing.

From Figures 6(c)-6(h), we have extracted the dominant frequency number of the receiving ultrasonic signals at every force number, and the evolution of dominant frequency is shown in Figure 6(b). In the whole loading process, the dominant frequencies of the receiving ultrasonic signals are almost not changed with the increase of the stress, and the dominant frequencies fluctuate in the vicinity of $30 \mathrm{kHz}$ which is the dominant frequency of the generated ultrasonic signals. So the following conclusion can be obtained, when the ultrasonic wave promulgates in coal or other materials, the dominant frequency of the signal remains unchanged and its amplitude attenuates, which is consistent with the literature [31].

\section{The Relation between Ultrasonic and Applied Load}

4.1. Statistical Analysis of Ultrasonic Parameters. We employed ultrasonic amplitude, amplitude of the dominant frequency and acoustic velocity to study the characteristics of sound wave responses of defects inside coal samples during the loading process. In the following, we provide a detailed introduction of the determination to the three ultrasonic wave values.

The ultrasonic amplitude is the maximum of the ultrasonic wave amplitudes. By applying the FFT, the frequency component with the maximum amplitude in the spectrum was defined as the dominant frequency. This maximum amplitude is the dominant frequency amplitude $[32,33]$. The determination of the two values is shown in Figures 7(a) and 7(b). The calculation of ultrasonic velocity is shown in Figure $7(\mathrm{c})$. Before calculating the velocity of ultrasonic signals, it is necessary to calibrate arrival time of received ultrasonic signals. The arrival time of ultrasonic waves before and after calibration is shown in Figure 7(c). In order to reduce the influence on the experimental results by the dispersion of coal samples, we conduct three sets of experiments and the ultrasonic response results of the three sets of experiments are shown in Table 3.

$$
v_{p}=\frac{d}{t_{1}-t_{0}},
$$

where $v_{p}$ is the acoustic velocity (longitudinal wave); $d$ is the distance of ultrasonic promulgation in the samples, which is the diameter of the samples; $t_{1}$ and $t_{0}$ are received time and transmitting time, respectively.

To study the relation between the inner structure of rocks and ultrasonic parameters, a regression equation is established between pressure level $x$ and ultrasonic parameter $Y$. According to the data from experiments, the polynomial of degree $k$ is used to fit their relation.

$$
Y=a_{k} x^{k}+\cdots+a_{2} x^{2}+a_{1} x+a_{0},
$$

where $Y$ is the acoustic parameter, which can be acoustic amplitude, amplitude of the dominant frequency, and acoustic velocity; $x$ is the stress level; $a_{0}, a_{1}, \ldots, a_{k}$ are the constant, leaner polynomial, ..., and polynomial of degree $k$, respectively.

Thus, the problem of polynomial regression can be converted into a multiple linear regression equation in a broad sense. Normally, with regard to a parabola that contains only one peak, the lower $k$ is 2 , which is a quadratic polynomial; in this experiment, two peaks exist, and $K$ must be greater than the number of peaks of the curve, so $k \geq 3$.

4.2. Relation between Ultrasonic Parameters and Mechanical Structure. From Table 3, we can know that, under the condition of the same applied load, the ultrasonic parameters (amplitude, amplitude of dominant frequency, and velocity) of the three sets of experiments are very close to each other and show the same change trend with the increasing load, so we used the average value of the three sets of experiments to establish the polynomial regression between the stress level and ultrasonic parameters. The regression curve of ultrasonic parameters against stress level is depicted in Figures 8(a), 8(b), and 8(c).

Results for regression equation of ultrasonic amplitude are as follows:

$$
\begin{aligned}
y= & 3.95 E-7 x^{4}-7.69 E-5 x^{3}+4.2 E-3 x^{2}-5.31 E \\
& -2 x+0.72, \quad R^{2}=0.8511 .
\end{aligned}
$$

Results for regression equation of amplitude of the dominant frequency are as follows:

$$
\begin{aligned}
y= & 3.49 E-5 x^{4}-6.65 E-3 x^{3}+0.35 x^{2}-3.36 x \\
& +31.06, \quad R^{2}=0.9205
\end{aligned}
$$


TABLE 3: The response result of ultrasonic parameters.

\begin{tabular}{|c|c|c|c|c|c|c|c|c|c|c|c|c|}
\hline \multirow{2}{*}{$\begin{array}{l}\text { Load } \\
(\mathrm{kN})\end{array}$} & \multicolumn{4}{|c|}{ Ultrasonic amplitude (V) } & \multicolumn{4}{|c|}{ Amplitude of dominant frequency $(\mathrm{mV})$} & \multicolumn{4}{|c|}{ Ultrasonic velocity $(\mathrm{m} / \mathrm{s})$} \\
\hline & & Test result & & Average & & Test result & & Average & & Test result & & Average \\
\hline 0 & 0.6823 & 0.6958 & 0.7282 & 0.7021 & 28.5487 & 32.1258 & 29.4266 & 30.0337 & 2236.8 & 1875.1 & 2031.2 & 2047.7 \\
\hline 1.5 & 0.6537 & 0.6593 & 0.6355 & 0.6495 & 30.7845 & 27.6520 & 31.1345 & 29.8570 & 2039.5 & 2365.3 & 2241.1 & 2215.3 \\
\hline 4.5 & 1.3081 & 1.3879 & 1.2949 & 1.3303 & 104.2894 & 109.3201 & 111.6916 & 108.4337 & 3058.2 & 2865.4 & 3067.1 & 2996.9 \\
\hline 7.5 & 1.1058 & 1.2360 & 1.0452 & 1.1290 & 73.3528 & 80.5934 & 66.1428 & 73.3630 & 2439.7 & 2647.2 & 2684 & 2590.3 \\
\hline 9 & 0.0952 & 0.0621 & 0.0614 & 0.0729 & 1.0892 & 0.3568 & 0.1710 & 0.5390 & 2348.1 & 1823.9 & 2123.2 & 2098.4 \\
\hline 10 & 0.0132 & 0.0189 & 0.0165 & 0.0162 & 0.0165 & 0.0097 & 0.0065 & 0.0109 & 1784.4 & 1501.8 & 1294.8 & 1527.0 \\
\hline 11 & 0.0028 & 0.0035 & 0.0030 & 0.0031 & 0.0020 & 0.0034 & 0.0030 & 0.0028 & 1627.0 & 1534.9 & 1468.3 & 1543.4 \\
\hline
\end{tabular}

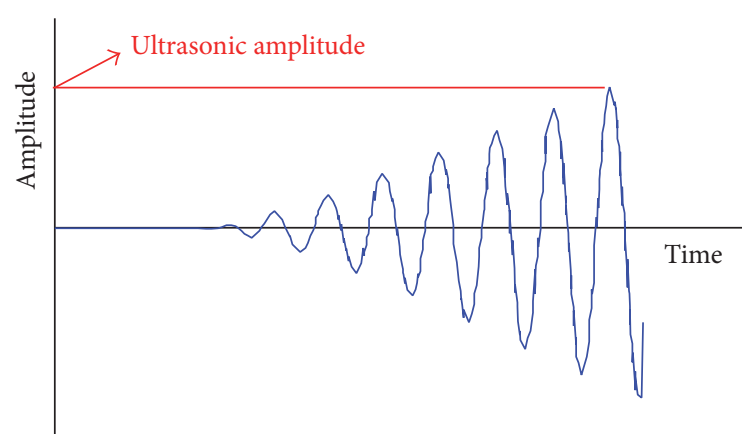

(a) Amplitude

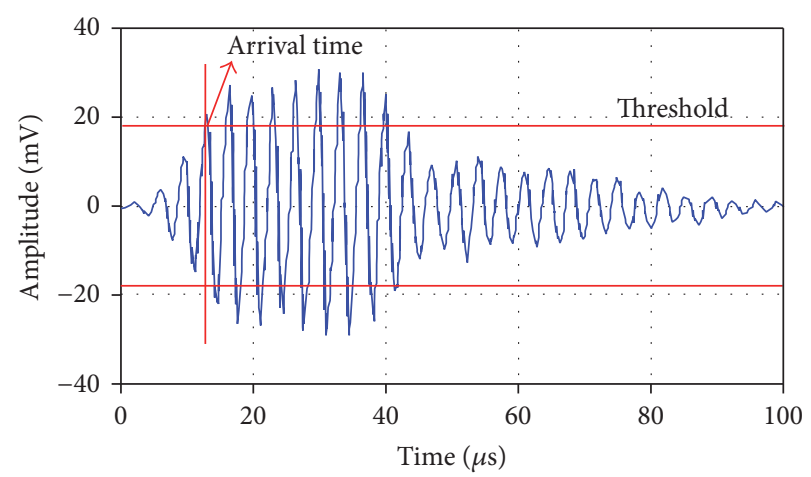

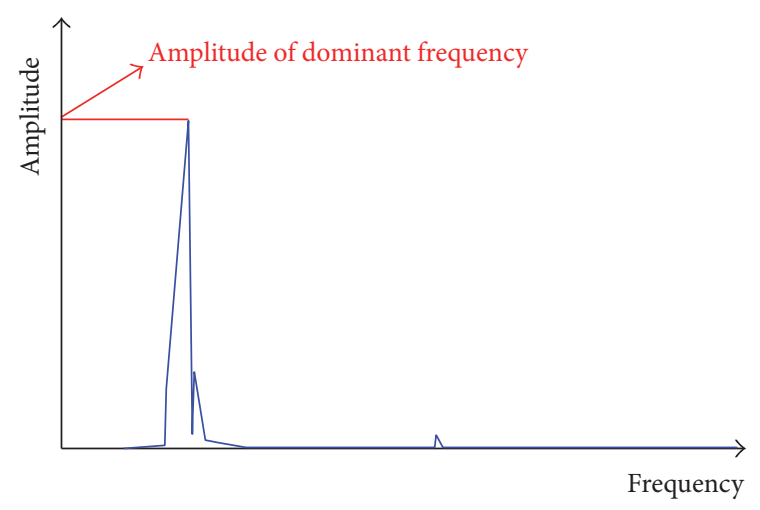

(b) Amplitude of dominant frequency

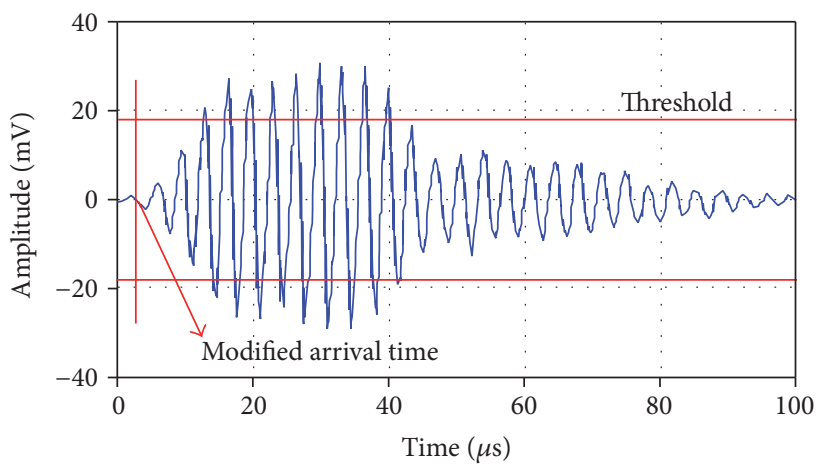

(c) Ultrasonic velocity

FIGURE 7: The determination of ultrasonic parameters.

Results for regression equation of ultrasonic velocity are as follows:

$$
\begin{aligned}
y= & 2.73 E-4 x^{4}-0.05 x^{3}+2.69 x^{2}-15.92 x \\
& +2052.86, \quad R^{2}=0.9549 .
\end{aligned}
$$

Figure 8 shows almost identical behavior among the different ultrasonic parameters. An ultrasonic wave would have a loss of energy when encountering defects. The ultrasonic velocity, amplitude, and amplitude of the dominant frequency are all the external appearance characterizing energy attenuation of ultrasonic promulgation [24]. So, as the stress level increases, variants of those values show almost the same trend.

At the beginning stage of loading, the parameters of ultrasonic signals show a fluctuation tendency. The ultrasonic amplitude and the amplitude of the dominant frequency show a slight decreasing tendency. The time taken by the wave to propagate shows a slight decrease and the ultrasonic velocity increases. As the loading pressure increases, the parameters of ultrasonic signals reach a peak value and then begin to decrease. As the loading stress increases further, ultrasonic amplitude, the dominant frequency amplitude, and ultrasonic velocity significantly decrease to reach the lowest value. After the fracture of coal subjected to loading pressure, the inner space of the coal is full of various macrocracks. 


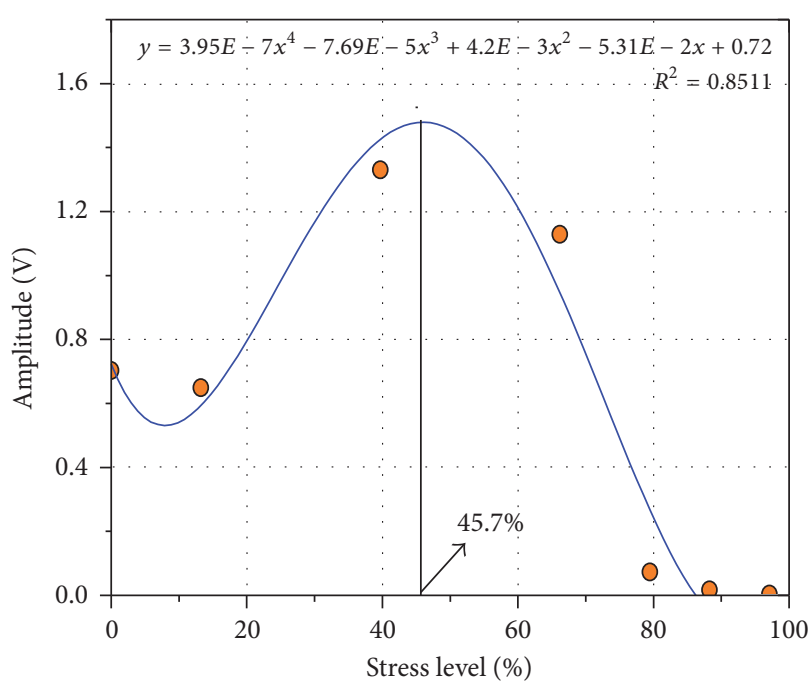

(a) Ultrasonic amplitude

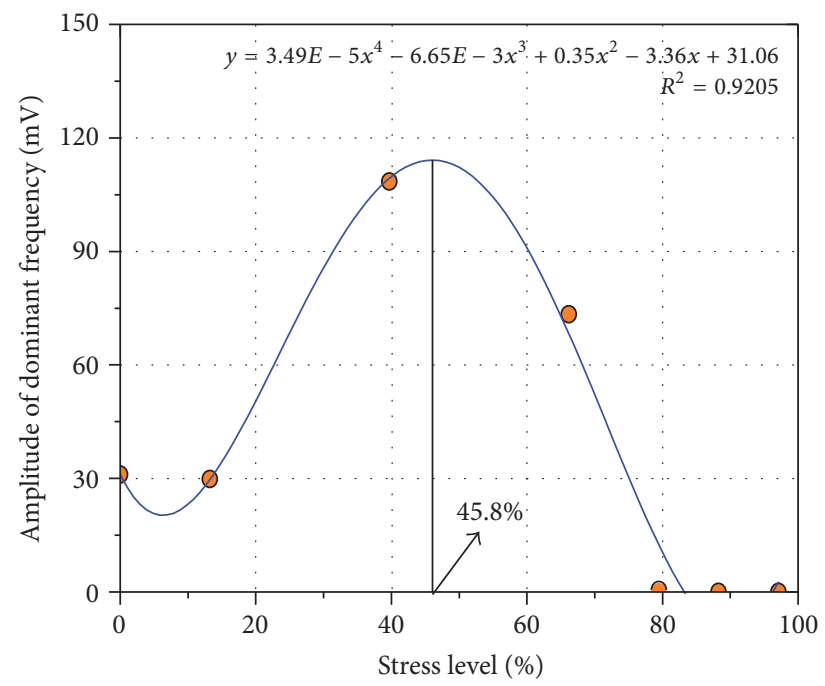

(b) Dominant frequency amplitude

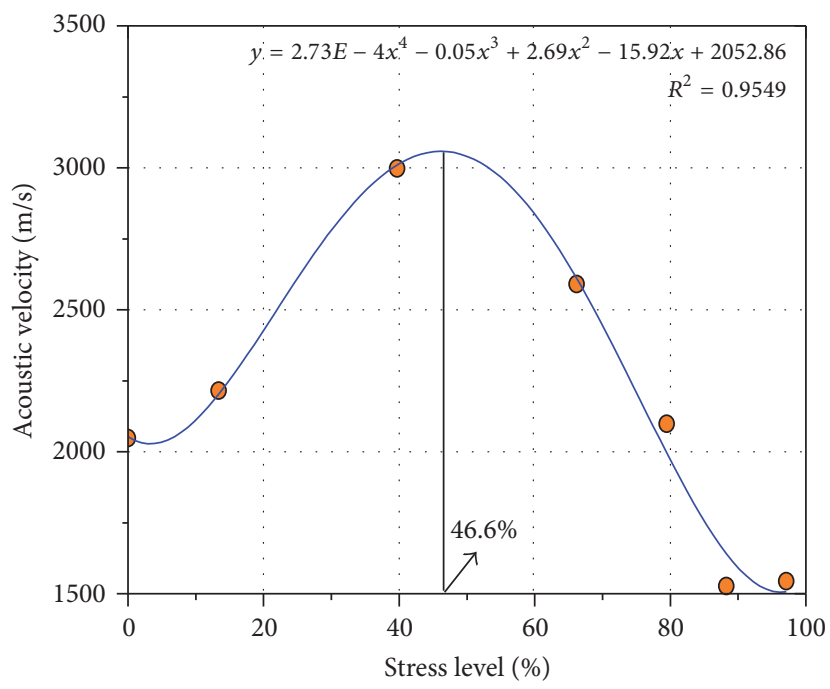

(c) Ultrasonic velocity

FIGURE 8: The result of regression equation of ultrasonic parameters.

These cracks spread throughout the coal surface, thereby significantly weakening the bearing capacity and integrity of the coal samples.

When the loading pressure equals roughly $46 \%$ of the maximum stress, the number of defects inside the coal begins to increase. At this moment, we define the very stress level (46\%) as stress threshold of the coal samples. Therefore, it can be concluded that if respondent measurements are considered to reduce the loading pressure of coal and rock samples before it reaches the stress threshold, the structural destruction inside coal can be reduced, such that rock or coal dynamical disasters can be avoided.

\section{Discussion}

Figure 8 shows almost identical behavior among the different ultrasonic parameters. And when the loading pressure equals roughly $46 \%$ of the maximum stress, the number of defects inside the coal begins to increase. Wang et al. [15] studied the relationship between ultrasonic velocity, crack width, and damage variable (Figure 9) of rock samples under the process of uniaxial compression. Here, we critically discussed this phenomenon in much more detail from the perspective of material damage mechanics.

In this paper, we use the damage variable $(D)$ introduced by Rabotnov et al. [34-36]. The damage variable is calculated according to the following:

$$
D=\frac{A^{*}}{A}=\frac{A-\widetilde{A}}{A}
$$

where $A$ is the initial cross-sectional area of the material, $A^{*}$ is the damage area, and $\widetilde{A}$ is the effective area. $D$ is the damage variable which varies from 0 to 1 . When $D=0$, it indicates 


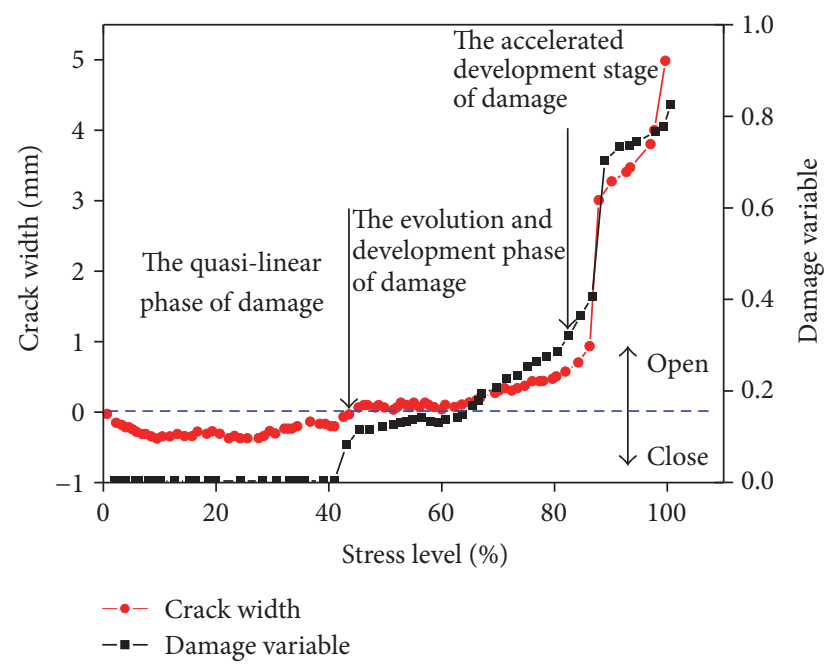

FIgURE 9: The evolution of crack width and damage variable [15].

that the material is in the state of no damage, while $D=1$ corresponds to the complete damage state of the material.

According to the knowledge of material mechanics, the stress $\sigma$ caused by force $F$ on the cross-sectional area $A$ is

$$
\sigma=\frac{F}{A}
$$

So, the effective stress $\widetilde{\sigma}$ on the effective cross-sectional area $\widetilde{A}$ is

$$
\widetilde{\sigma}=\frac{F}{\widetilde{A}} .
$$

By combining formulae (7)-(9), we can obtain

$$
\widetilde{\sigma}=\frac{\sigma}{1-D}
$$

Known as the hypothesis of strain equivalence [37, 38], strain caused by stress $\sigma$ acting on the material damage and strain caused by effective stress $\widetilde{\sigma}$ acting on nondestructive material are equivalent, namely,

$$
\varepsilon=\frac{\sigma}{\widetilde{E}}=\frac{\widetilde{\sigma}}{E},
$$

where $E$ is the elastic modulus of the material, $\sigma$ is the stress, $\varepsilon$ is the strain, and $\widetilde{\sigma}$ is the effective stress.

By combining formula (10) and formula (11), the damage variable $D$ can be obtained as follows:

$$
D=1-\frac{\sigma}{\varepsilon E}
$$

The changing pattern of damage variable $D$ as the stress level changes in the loading process is shown in Figure 10.

From Figure 10, we can see that damage variable decreases first and then increases as the stress level increases. At the stress level of $40 \% \sim 50 \%$, damage variable $D$ reaches its minimum. Later, the damage began to increase rapidly, which corresponds to the response characteristics of ultrasonic parameters in the loading process. In other words, the ultrasonic technology can reflect the damage evolution of coal and rock under loading and evaluate the stress state of coal or rock. It is also a good tool to monitor and early warn the coal or rock dynamic disasters.

In this article, ultrasonic techniques were used to study the changing pattern of damage and defects inside coal samples in the process of distortion and destruction, and a series of valuable conclusions were obtained. However, owing to the specificity of coal sample characteristics and the limitation of laboratory conditions, further studies should be carried out on acoustic parameters of ultrasonic signals and the quantitative analysis of damage and defects inside coal samples undergoing load pressure. In addition, the following tests are recommended: (1) analyze the ultrasonic characteristics of testing samples in the whole loading process and the responses of the ultrasonic amplitude, amplitude of the dominant frequency, and acoustic velocity to the whole stress level. This requires an emphasis on finding the difference of waveform and frequency between the AE signals and ultrasonic signals. And obviate the passive signals (AE) during the loading process via a data processing method such as wavelet transformation rather than the control loading method. (2) Reveal the relations among defect characteristics, defect extent, and ultrasonic parameters by employing wave theory of elastic waves, fracturing mechanics, and defect mechanics using SEM and CT scanning. This would be helpful in field application via ultrasonic test results of coal assessing the dynamic defect characteristics of coal.

\section{Conclusion}

In this article, an ultrasonic testing system of coal is established, and the variations in the propagation of ultrasonic signals through coal samples are studied. The following conclusions are proposed based on the experiments carried out in this study.

In the loading process, coal samples generate AE signals, which affect the outcome of the test results. To reduce or avoid the influence of the AE signals generated during the process of distortion and fracturing of coal samples undergoing load pressure, the ultrasonic testing method should be conducted by subjecting coal to a constant load. At the initial loading stage, the ultrasonic amplitude, amplitude of the dominant frequency, and wave velocity slightly decrease as the loading process progresses, and these three ultrasonic parameters gradually increase to their maxima when the stress level reaches approximately $46 \%$. When it progresses from the linear elastic stage to the elastic plastic stage, the material inside the coal distorts and fractures more drastically, the inner defects are fully developed, and the acoustic parameters decrease significantly.

When the loading pressure equals roughly $46 \%$ of the maximum stress, the number of defects inside the coal begins to increase. If the corresponding measurements are considered to reduce the loading pressure before the loading pressure of the coal or rock samples reaches its stress threshold, the structural destruction inside coal can be reduced, such that rock or coal dynamical disasters can be avoided. 

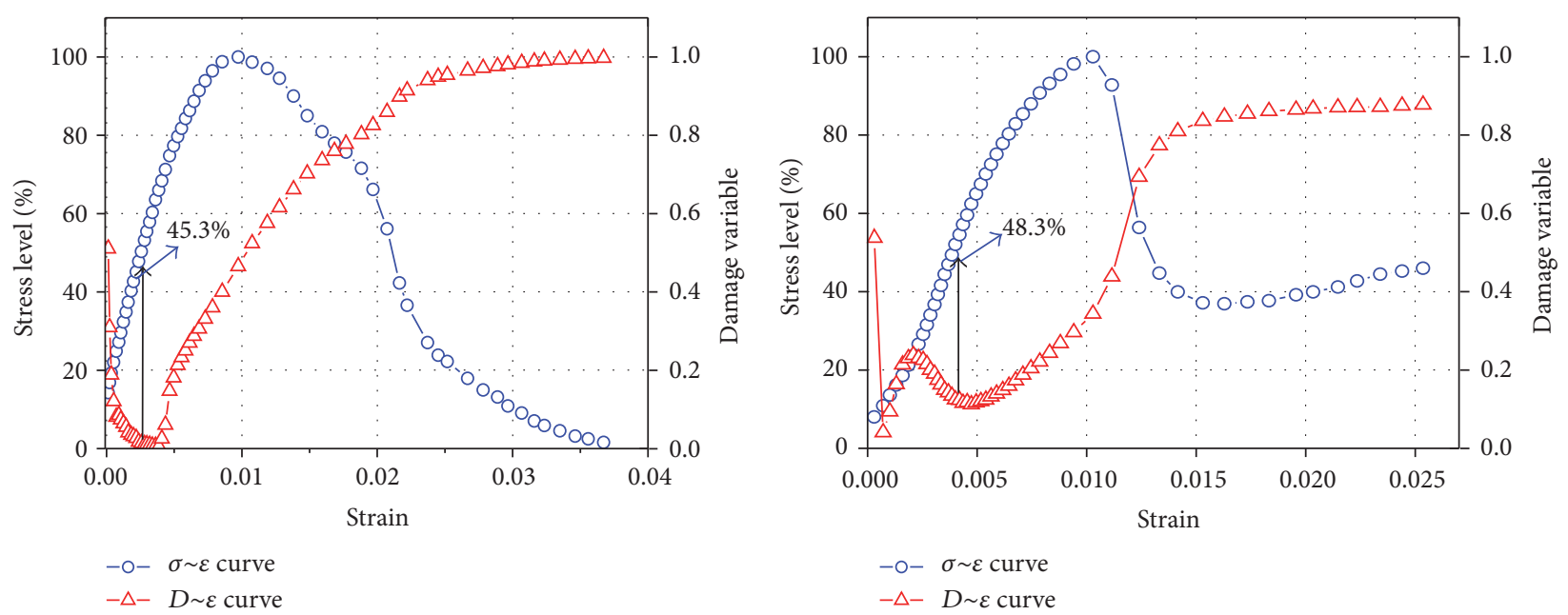

FIGURE 10: The evolution curves of damage strain stress for coal samples.

\section{Competing Interests}

The authors declare that they have no competing interests.

\section{Acknowledgments}

This work is supported by the Fundamental Research Funds for the Central Universities (2014ZDPY23), Excellent Innovation Team of China University of Mining and Technology (2014ZY001), the State Key Research Development Program of China (Grant no. 2016YFC0801401), and a project funded by the Priority Academic Program Development of Jiangsu Higher Education Institutions (PAPD). The authors are grateful to all the coal mines mentioned in the paper for providing experimental coal samples.

\section{References}

[1] J. P. Wei, H. L. Wang, D. K. Wang, and B. H. Yao, "An improved model of gas flow in coal based on the effect of penetration and diffusion," Journal of China University of Mining \& Technology, vol. 45, no. 5, pp. 873-878, 2016.

[2] B. Yao, Q. Ma, J. Wei, J. Ma, and D. Cai, "Effect of protective coal seam mining and gas extraction on gas transport in a coal seam," International Journal of Mining Science and Technology, vol. 26, no. 4, pp. 637-643, 2016.

[3] X. L. Li, E. Y. Wang, Z. H. Li, Z. T. Liu, D. Z. Song, and L. M. Qiu, "Rock burst monitoring by integrated microseismic and electromagnetic radiation methods," Rock Mechanics \& Rock Engineering, vol. 49, no. 11, pp. 4393-4406, 2016.

[4] C. Mark and M. Gauna, "Evaluating the risk of coal bursts in underground coal mines," International Journal of Mining Science and Technology, vol. 26, no. 1, pp. 47-52, 2016.

[5] J. Liu, E. Wang, D. Song, S. Wang, and Y. Niu, "Effect of rock strength on failure mode and mechanical behavior of composite samples," Arabian Journal of Geosciences, vol. 8, no. 7, pp. 45274539, 2015.

[6] H. W. Zhang, H. Rong, J. Q. Chen et al., "Geo-dynamic condition evaluation method for rockburst in suberect and extremely thick coal seam," Journal of China University of Mining \& Technology, vol. 44, no. 6, pp. 1053-1060, 2015.

[7] S.-Q. Yang, C.-H. Lu, and T. Qu, "Investigations of crack expansion in marble having a single pre-existing hole: experiment and simulations," Journal of China University of Mining and Technology, vol. 38, no. 6, pp. 774-781, 2009.

[8] L. Wu, S. Liu, Y. Wu, and H. Wu, "Changes in infrared radiation with rock deformation," International Journal of Rock Mechanics and Mining Sciences, vol. 39, no. 6, pp. 825-831, 2002.

[9] M. H. B. Nasseri, F. Rezanezhad, and R. P. Young, "Analysis of fracture damage zone in anisotropic granitic rock using $3 \mathrm{D} \mathrm{X}$ ray CT scanning techniques," International Journal of Fracture, vol. 168, no. 1, pp. 1-13, 2011.

[10] R. Zhang, T. Ai, H. Li, Z. Zhang, and J. Liu, "3D reconstruction method and connectivity rules of fracture networks generated under different mining layouts," International Journal of Mining Science and Technology, vol. 23, no. 6, pp. 863-871, 2013.

[11] E. Aker, D. Kühn, V. Vavryčuk, M. Soldal, and V. Oye, "Experimental investigation of acoustic emissions and their moment tensors in rock during failure," International Journal of Rock Mechanics and Mining Sciences, vol. 70, pp. 286-295, 2014.

[12] H. P. Xie, J. F. Liu, Y. Ju, J. Li, and L. Z. Xie, "Fractal property of spatial distribution of acoustic emissions during the failure process of bedded rock salt," International Journal of Rock Mechanics and Mining Sciences, vol. 48, no. 8, pp. 1344-1351, 2011.

[13] N. Li, M. Ge, and E. Wang, "Two types of multiple solutions for microseismic source location based on arrival-time-difference approach," Natural Hazards, vol. 73, no. 2, pp. 829-847, 2014.

[14] Q.-Y. Li, L.-J. Dong, X.-B. Li, Z.-Q. Yin, and X.-L. Liu, "Effects of sonic speed on location accuracy of acoustic emission source in rocks," Transactions of Nonferrous Metals Society of China, vol. 21, no. 12, pp. 2719-2726, 2011.

[15] Y. Wang, X. Li, R. L. Hu et al., "Review of research process and application of ultrasonic testing for rock and soil," Journal of Engineering Geology, vol. 23, no. 2, pp. 287-300, 2015.

[16] M. A. El-Gohary, "Evaluation of treated and un-treated Nubia Sandstone using ultrasonic as a non-destructive technique," Journal of Archaeological Science, vol. 40, no. 4, pp. 2190-2195, 2013. 
[17] T. Lokajíček and T. Svitek, "Laboratory measurement of elastic anisotropy on spherical rock samples by longitudinal and transverse sounding under confining pressure," Ultrasonics, vol. 56, pp. 294-302, 2015.

[18] J. Coe and S. J. Brandenberg, "P-wave reflection imaging of submerged soil models using ultrasound," Journal of Geotechnical and Geoenvironmental Engineering, vol. 136, no. 10, Article ID 013010QGT, pp. 1358-1367, 2010.

[19] L. Peyras, P. Rivard, P. Breul, A. Millet, and G. Ballivy, "Characterization of rock discontinuity openings using acoustic wave amplitude-application to a metamorphic rock mass," Engineering Geology, vol. 193, pp. 402-411, 2015.

[20] L. Adam, K. van Wijk, T. Otheim, and M. Batzle, "Changes in elastic wave velocity and rock microstructure due to basalt$\mathrm{CO}_{2}$-water reactions," Journal of Geophysical Research: Solid Earth, vol. 118, no. 8, pp. 4039-4047, 2013.

[21] T. Engelder and R. Plumb, "Changes in in situ ultrasonic properties of rock on strain relaxation," International Journal of Rock Mechanics and Mining Sciences and, vol. 21, no. 2, pp. 7582, 1984.

[22] A. Nur, "Effects of access on velocity anisotropy in rocks with cracks," Rock Mechanics and Engineering Geology, vol. 76, no. 8, pp. 2002-2034, 1971.

[23] G.-P. Zheng, X.-D. Zhao, J.-P. Liu, and Y.-H. Li, "Experimental study on change in acoustic wave velocity when rock is loading," Journal of Northeastern University, vol. 30, no. 8, pp. 1197-1200, 2009.

[24] K. Zhao, J.-F. Jin, X.-J. Wang, and K. Zhao, "Study on rock damage and acoustic emission based on ultrasonic velocity test of rock specimen under uniaxial compression," Rock and Soil Mechanics, vol. 28, no. 10, pp. 2105-2114, 2007.

[25] D. Xi, C. Zhang, and X. Liu, "Wave velocities, modulus, fatigue damage of sandstone under low confining pressure and cyclic loading (II): mechanics characteristics of rock," Chinese Journal of Rock Mechanics and Engineering, vol. 24, no. 13, pp. 2168-2171, 2004.

[26] J. Dvorkin and A. Nur, "Dynamic poroelasticity: a unified model with the squirt and the Biot mechanisms," Geophysics, vol. 58, no. 4, pp. 524-533, 1993.

[27] M. S. Diallo, M. Prasad, and E. Appel, "Comparison between experimental results and theoretical predictions for P-wave velocity and attenuation at ultrasonic frequency," Wave Motion, vol. 37, no. 1, pp. 1-16, 2003.

[28] C. McCann and J. Sothcott, "Sonic to ultrasonic Q of sandstones and limestones: laboratory measurements at in situ pressures," Geophysics, vol. 74, no. 2, pp. WA93-WA101, 2009.

[29] A. Lavrov, "The Kaiser effect in rocks: principles and stress estimation techniques," International Journal of Rock Mechanics and Mining Sciences, vol. 40, no. 2, pp. 151-171, 2003.

[30] N. Li, E.-Y. Wang, E.-L. Zhao, Y.-K. Ma, F.-L. Xu, and W.-H. Qian, "Experiment on acoustic emission of rock damage and fracture under cyclic loading and multi-stage loading," Journal of the China Coal Society, vol. 35, no. 7, pp. 1099-1103, 2010.

[31] R. Li and W. B. Jian, "Study on acoustic property in fatigue damage process of fractured rocklike materials," Journal of Water Resources and Architectural Engineering, vol. 12, no. 3, pp. 115$120,2014$.

[32] Q.-Q. Ni and M. Iwamoto, "Wavelet transform of acoustic emission signals in failure of model composites," Engineering Fracture Mechanics, vol. 69, no. 6, pp. 717-728, 2002.
[33] W. Mao and I. Towhata, "Monitoring of single-particle fragmentation process under static loading using acoustic emission," Applied Acoustics, vol. 94, pp. 39-45, 2015.

[34] Y. N. Robotnov, "Creep rupture in applied mechanics," in Proceedings of the 12th International Congress on Applied Mechanics, pp. 342-349, 1968.

[35] Y. N. Robotnov, Creep Problems in Structural Members, NorthHolland, Amsterdam, The Netherlands, 1969.

[36] V. A. Robsman and G. N. Nikogosyan, "Changes in emission spectra during crack development and rock failure," Transactions (Doklady) of the USSR Academy of Sciences: Earth Science Sections, vol. 306, no. 3, pp. 26-29, 1990.

[37] Y. Ju and H. P. Xie, "A variable condition of the damage description based on hypothesis of strain equivalence," Chinese Journal of Applied Mechanics, vol. 15, no. 1, pp. 43-49, 1998.

[38] T. Wen, H. M. Tang, Y. R. Liu, Z. X. Zou, K. Wang, and C. Y. Lin, "Newly modified damage statistical constitutive model of rock based on impact factor," Journal of Chinese University of Mining \& Technology, vol. 45, no. 1, pp. 141-149, 2016. 


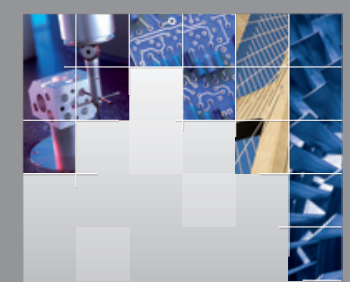

\section{Enfincering}
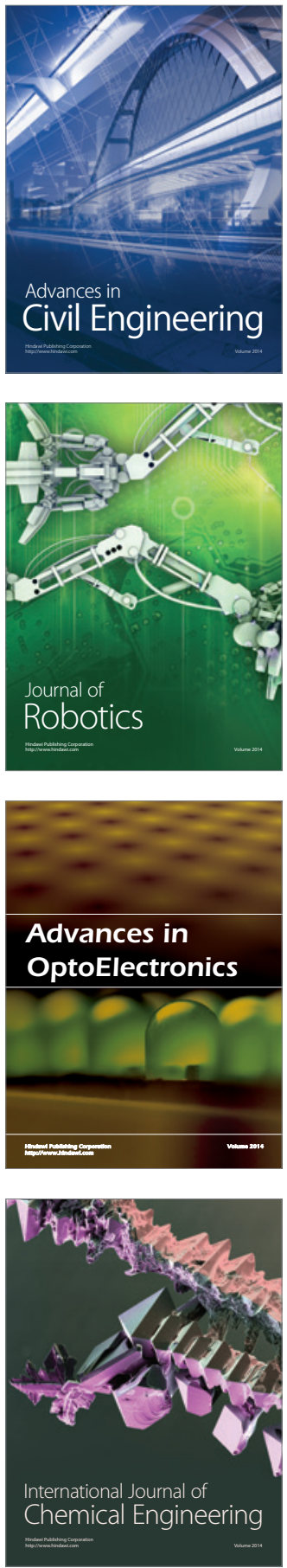

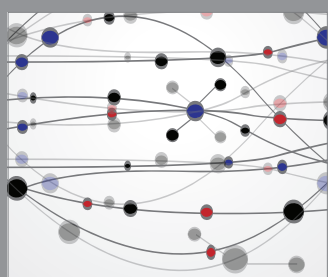

The Scientific World Journal

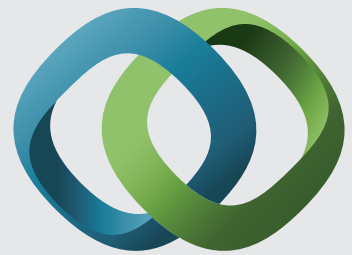

\section{Hindawi}

Submit your manuscripts at

https://www.hindawi.com
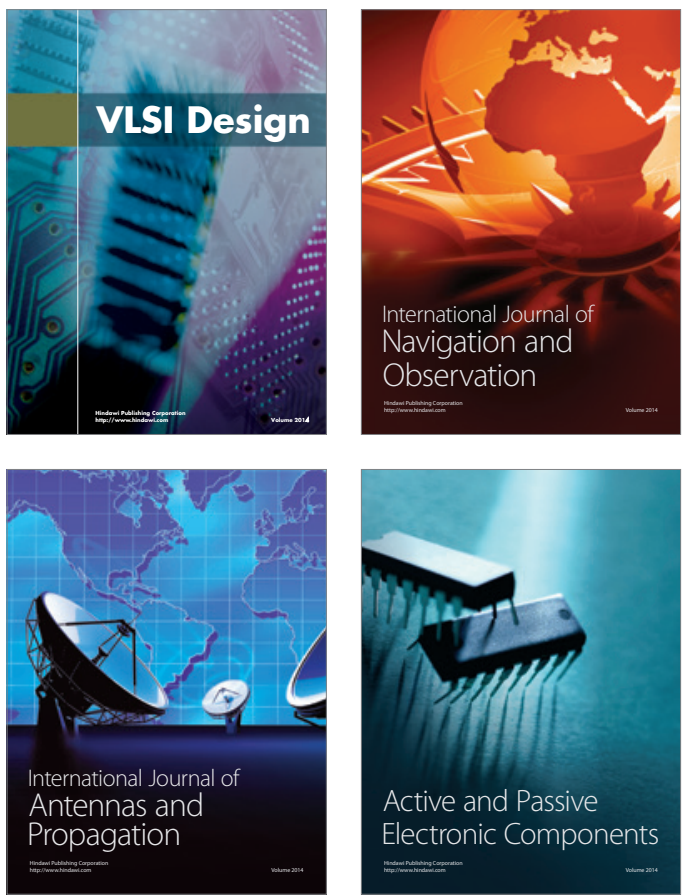
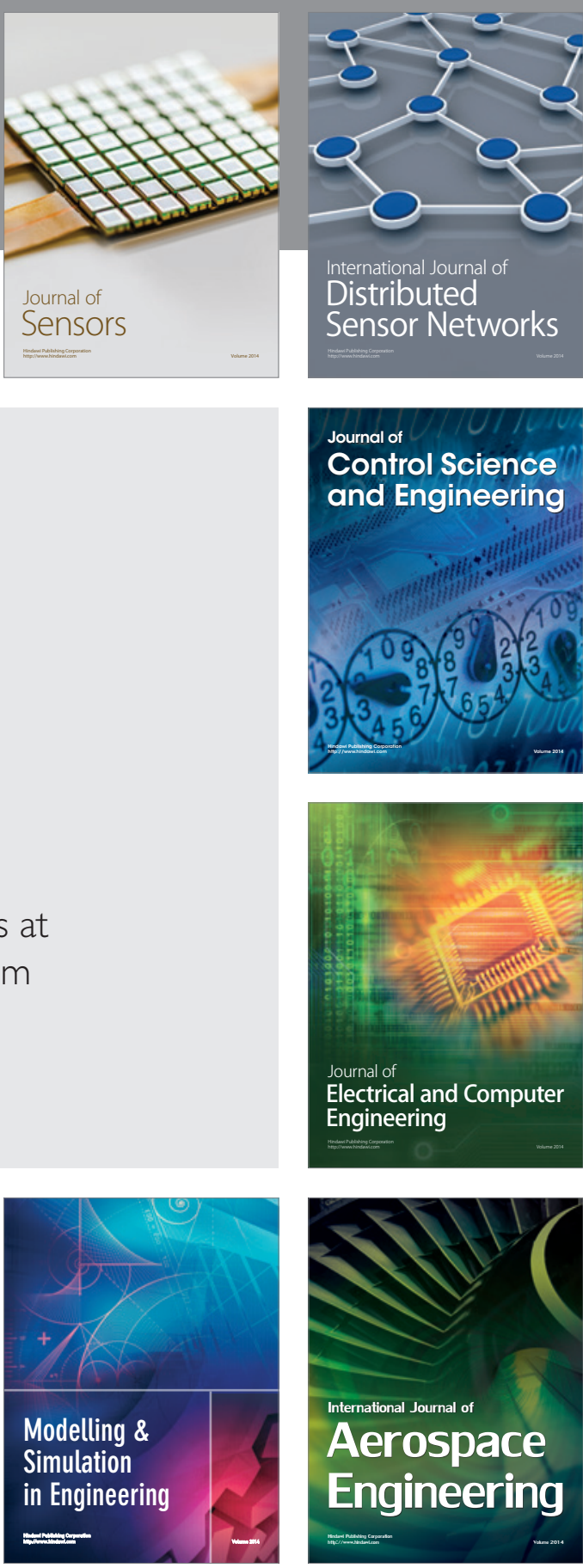

International Journal of

Distributed

Sensor Networks

$-$

Joumal of

Control Science

and Engineering
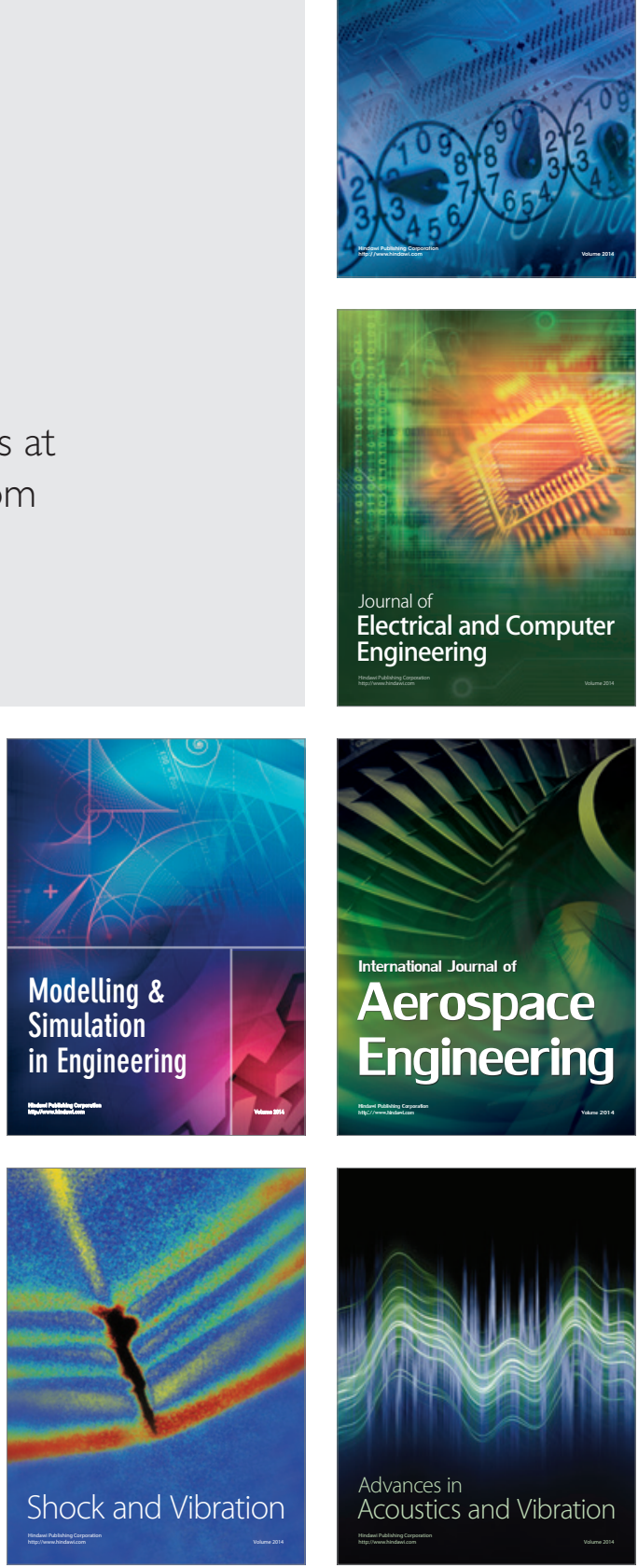